\title{
Recording puff volume in smoking
}

\author{
STEVEN W. GUST and ROY W. PICKENS \\ Department of Psychiatry, School of Medicine \\ University of Minnesota, Minneapolis, Minnesota 55455 \\ and \\ TERRY F. PECHACEK \\ Laboratory of Physiological Hygiene, School of Public Health \\ University of Minnesota, Minneapolis, Minnesota 55455
}

\begin{abstract}
Recent research on nicotine self-administration has highlighted the need to accurately assess within-cigarette topography in order to estimate changes in puff profiles that occur in response to varying nicotine content. This paper describes equipment and techniques that may be used to record puff volume in the laboratory and discusses methods used by other researchers to study puff volume with an emphasis on methodological advantages of the present technique.
\end{abstract}

A recent estimate placed the number of tobacco smokers in the United States at more than 52 million (Moss, 1979). Moreover, while most adult smokers express an interest in quitting, approximately 60\%$80 \%$ have tried to quit and failed (Moss, 1979). Because of the grave health consequences of smoking (United States Public Health Service, Note 1), there has been continuing interest in the development of strategies to aid smokers to quit. However, cessation strategies typically show only a $20 \%$ to $30 \%$ long-term abstinence rate, which is comparable to the spontaneous cessation rate in the general population (Pechacek, 1979). Because of this low cessation rate, there is a growing consensus that there is an inadequate understanding of the variables controlling smoking behavior.

The analysis of smoking behavior has proved difficult because smoking is a multiple operant consisting of many response topographies. Individual response components include frequency (number of cigarettes, number of puffs), durational (puff duration, interpuff interval, cigarette duration, intercigarette interval), and volumetric (puff volume, inhalation volume) characteristics. Identification and measurement of these topographies are believed to be important in the analysis of smoking behavior, as their interaction is believed to determine actual smoke exposure (Fredericksen \& Martin, 1979). Single measures of smoking, such as counting the number of cigarettes smoked (Goldfarb, Jarvik, \& Glick, 1970; Henningfield, Stitzer, \& Griffiths,

The authors would like to thank John R. Hughes for his assistance in this project. Requests for reprints should be sent to Steven W. Gust, Psychiatry Department, Box 392, Mayo Memorial Building, University of Minnesota Hospitals, University of Minnesota, Minneapolis, Minnesota 55455. This research was supported by NIDA Research Grant DA-02413.
1980; Russell, Wilson, Patel, Cole, \& Feyerabend, 1973; Russell, Wilson, Patel, Feyerabend, \& Cole, 1975), may be improved by monitoring individual differences in smoking pattern that may affect actual smoke exposure. This paper describes a methodology for the laboratory measurement of puff volume, one aspect of smoking topography that has been found to be a good predictor of lung exposure to gaseous substances (Sheahan, Pavia, Bateman, Agnew, \& Clark, 1980).

Puff volume has proved difficult to measure. Techniques reported in the literature include (1) estimation of relative puff volume by graphical integration of the area under the respiration curve, (2) estimation of puff volume from the vacuum produced in a cigarette holder during puffing, and (3) estimation of puff volume by continuous integration of flow rate as measured by pressure drop during a puff.

Gritz (Note 2) used the approximate area under the curve of respiration during a puff as a method of relative puff volume. The respiration curve was obtained by using a thermistor-containing cigarette holder. When operated in a self-heated mode, a voltage output proportional to flow was obtained and subsequently integrated to yield volume. Kumar, Cooke, Lader, and Russell (1975) report on the effects of nicotine on puffing variables including puff volume, but they report only that volume was estimated from puff duration and inhalation depth, with no description of how this was done.

Dunn and Freiesleben (1978) obtained a measure of relative volume by using a differential pressure transducer. This device was connected to a Teflon cigarette holder by plastic tubing and measured the pressure change (vacuum) in the cigarette holder during puffing. The maximum pressure change obtained during each puff measured puffing rate; volume was then calculated 
as the product of puff duration and puffing rate. Herning, Jones, Bachman, and Mines (1981), using a similar measurement technique, calibrated the device by passing air through it at known rates while the corresponding pressure change was determined. Nonlinear regression was then used to derive a quadratic equation relating pressure drop and flow rate. Puff volume was computed by numerical integration of the flow rate during the puff. The accuracy of the technique used by Dunn and Freiesleben and Herning et al. has recently been questioned (Rawbone, 1981).

Another group of studies used a more sophisticated procedure for measuring puff volume that involved measurement of the pressure drop across a small resistance inserted between the cigarette and the smoker. In this situation, when there is air flow during puffing, the pressure drop created across the resistance is related to the flow rate. Puff volume can then be derived by integration of the flow signal across time.

Adams (1978) and Guillerm and Radziszewski (1978) used a flowmeter incorporated into the cigarette filter. The pressure drop was measured across either side of a wire gauge screen inset in the filter. This procedure presumes that the resistance to flow caused by the screen is constant at any particular flow rate and that the effect is linear at different flow rates. No calibration data were presented, however, so it is difficult to assess the validity of this procedure. The linearity of the relationship between flow rate and pressure change with this design would be affected by several factors: (1) changes in screen resistance during the smoking of a cigarette due to the deposition of particulate matter on the screen, and (2) characteristics of the screen itself.

Rawbone, Murphy, Tate, and Kane (1978) used a device similar to that of Guillerm and Radziszewski (1978) to measure puff volume. Their flowmeter contained a 6-mm cellulose acetate filter insert inside the cigarette holder. The pressure drop across the filter was measured by a differential pressure transducer, and puff volume was calculated by integration of the flow signal across time. A major assumption underlying this procedure is that flow rate is linearly related to pressure drop. Rawbone et al. present data showing that this was not the case over the range of flow rates normally found in cigarette puffing $(0-5,000 \mathrm{ml} / \mathrm{min})$. Another problem concerns the collection of condensate in the filter insert during smoking, which may alter the permeability and resistance of the filter and, therefore, the volume measured.

In summary, even the most detailed and careful techniques for measuring puff volume have not controlled for (1) permeability changes of filters due to accumulation of particulate matter while a cigarette is smoked and (2) nonlinear relationships between flow rate and pressure drop. Furthermore, these studies are confounded by the changes in smoking behavior that may be caused by the placement of a resistance between the cigarette and the smoker.

A method of measuring puff volume that avoids some of these problems was designed and implemented for study of smoking behavior in our laboratory. The method of puff volume measurement is illustrated in Figure 1. Puff volume is measured by inhaling air for cigarette combustion through a pneumotachograph (Fleisch Model 00). The relationship between flow rate and pressure change for this device is linear over the normal range of puffing rates $(0-100 \mathrm{ml} / \mathrm{sec})$. To obtain puff volume, the cigarette is placed in a cigarette holder that has been mounted through the center of a rubber stopper. Before each puff on the cigarette, the subject places the stopper containing the cigarette into one end of a plastic cylinder. The stopper is removed after each puff, allowing the cigarette to burn freely. The plastic cylinder is connected at the other end to a pneumotachograph by a 20 -in. length of .25 -in.-inside-diameter plastic tubing. Thus, when the subject puffs on the cigarette, air is drawn through the pneumotachograph (in which its volume is measured), into the plastic cylinder for tobacco combustion, and then into the subject's mouth. Such an arrangement prevents the passage of cigarette smoke through the pneumotachograph itself, while still allowing measurement of puff volume. Thus, the pneumotachograph is not affected by the particulate matter from the cigarette smoke.

The pressure change created in the pneumotachograph by cigarette puffing is converted into an electrical signal by a differential pressure transducer (Gould Statham PM15E) and recorded on a dynograph (Beckman R511A). The signal from the pressure transducer is also fed into an integrator coupler (Beckman Type $9873 \mathrm{~B}$ resetting integrator coupler) that mathematically integrates the flow rate over the duration of

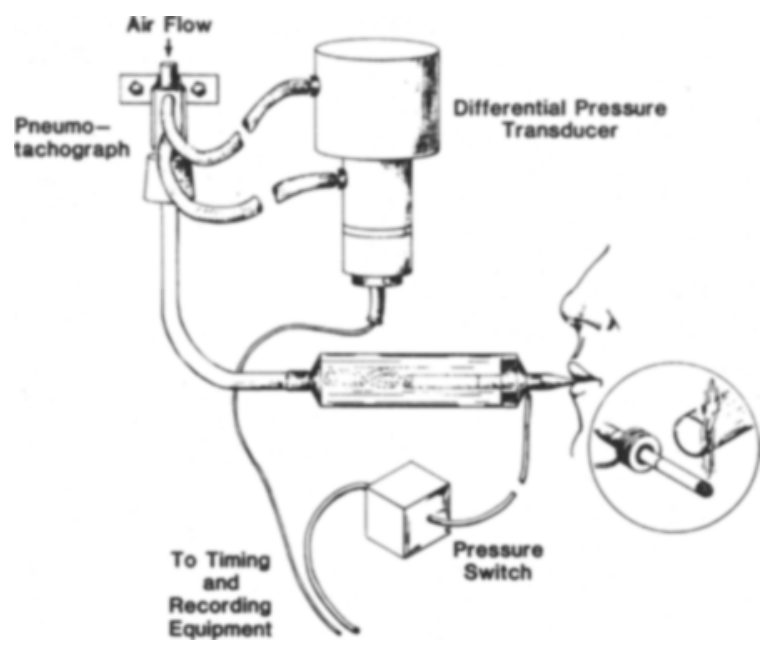

Figure 1. Schematic diagram of smoking topography measuring devices. See text for details. 
the puff interval to give puff volume. A series of calibration pulses of normal puff size $(10-80 \mathrm{ml})$ was found to show a high degree of linearity $(r=.99)$ between calibration pulses and puff volume measured. Such a procedure gives an accurate measure of smoke drawn into the mouth during the puff.

This method has several advantages over other reported techniques for recording puff volume. Specifically, it (1) eliminates errors due to changing resistance characteristics of a filter during a cigarette due to the deposition of particulate matter, (2) causes no changes in smoking topography due to changes in draw resistance caused by the insertion of a filter between the cigarette and the smoker, and (3) uses a flow measuring technique based on a linear flow rate measurement.

\section{REFERENCE NOTES}

1. United States Public Health Service. The health consequences of smoking. Washington, D.C: United States Department of Health, Education, and Welfare, 1979.

2. Gritz, E. R. Patterns of puffing in cigarette smokers. In N. A. Krasnegor (Ed.), Self-administration of abused substances: Methods for study (NIDA Research Monograph 20). DHEW, ADAMHA, July 1978.

\section{REFERENCES}

Adams, P. I. The influence of cigarette smoke yields on smoking habits. In R. E. Thornton (Ed.), Smoking behavior: Physiological and psychological influences. New York: Churchill Livingstone, 1978.

Dunn, P. J., \& Freiesleben, E. R. The effects of nicotineenhanced cigarettes on human smoking parameters and alveolar carbon monoxide levels. In R. E. Thornton (Ed.), Smoking behavior: Physiological and psychological influences. New York: Churchill Livingstone, 1978.

Frederiksen, L. W., \& Martin, J. E. Carbon monoxide and smoking behavior. Addictive Behaviors, 1979, 4, 21-30.

Goldfarb, R., Jarvik, M. E., \& Glick, S. D. Cigarette nicotine- content as a determinant of human smoking behavior. Psychopharmacologia, 1970, 17, 89-93.

Guillerm, R., \& RADziszewski, E. Analysis of smoking pattern including intake of carbon monoxide and influences of change in cigarette design. In R. E. Thornton (Ed.), Smoking behavior: Physiological and psychological influences. New York: Churchill Livingstone, 1978.

Henningfield, J. E., Stitzer, M. L., \& Griffiths, R. R. Expired air carbon monoxide accumulation and elimination as a function of number of cigarettes smoked. Addictive Behaviors, $1980,5,265-272$

Herning, R. I., Jones, R. T., Bachman, J., \& Mines, A. H. Puff volume increases when low nicotine cigarettes are smoked. British Medical Journal, 1981, 283, 187-189.

Kumar, R., Cooke, E. L., Lader, M. H., \& Russell, M. A. H. Is nicotine important in tobacco smoking? Clinical Pharmacology and Therapeutics, 1975, 17, 520-529.

Moss, A. J. Changes in cigarette smoking and current smoking practices among adults. United States, 1978. Advance Data, $1979,52,1-22$.

Pechace K, T. F. Modification of smoking behavior. In USPHS, Smoking and health, A report of the Surgeon General. Washington: U.S. Government Printing Office, 1979.

Rawbone, R. G. Puff volume increases when low nicotine cigarettes are smoked. British Medical Journal, 1981, 283, 498. (Letter)

Rawbone, R. G., Murphy, K., Tate, M. E., \& Kane, S. J. The analysis of smoking parameters: Inhalation and absorption of tobacco smoke in studies of human smoking behavior. In R. E. Thornton (Ed.), Smoking behavior: Physiological and psychological influences. New York: Churchill Livingstone, 1978.

Russell, M. A. H., Wilson, C., Patel, U. A., Cole, P. V., \& Feyerabend, C. Comparison of effect on tobacco consumption and carbon monoxide absorption of changing to high and low nicotine cigarettes. British Medical Journal, 1973, 4, 512516.

Rusbell, M. A. H., Wilson, C., Patel, U. A., Feyerabend, C., \& Cole, P. V. Plasma nicotine levels after smoking cigarettes with high, medium, and low nicotine yields. British Medical Journal, 1975, 2, 414-416.

Sheahan, N. F., Pavia, D., Bateman, J. R. M., Agnew, J., \& Clark, S. W. A technique for monitoring the inhalation of cigarette smoke in man, using Krypton-81 nm. International Journal of Applied Radiation and Isotopes, 1980, 31, 438-441.

(Received for publication August 9, 1982; revision accepted November 12,1982 .) 